\title{
Preliminary guideline- and pathophysiology-based protocols for neurocritical care
}

\author{
Yasuhiro Norisue $^{1,2^{*}}$ (D), Yoshihisa Fujimoto ${ }^{1}$ and Kazuma Nakagawa ${ }^{3}$
}

\begin{abstract}
Background: Because of the complex pathophysiological processes involved, neurocritical care has been driven by anecdotal experience and physician preferences, which has led to care variation worldwide. Standardization of practice has improved outcomes for many of the critical conditions encountered in the intensive care unit.

Main body: In this review article, we introduce preliminary guideline- and pathophysiology-based protocols for (1) prompt shivering management, (2) traumatic brain injury and intracranial pressure management, (3) neurological prognostication after cardiac arrest, (4) delayed cerebral ischemia after subarachnoid hemorrhage, (5) nonconvulsive status epilepticus, and (6) acute or subacute psychosis and seizure.

Conclusion: These tentative protocols may be useful tools for bedside clinicians who need to provide consistent, standardized care in a dynamic clinical environment. Because most of the contents of presented protocol are not supported by evidence, they should be validated in a prospective controlled study in future. We suggest that these protocols should be regarded as drafts to be tailored to the systems, environments, and clinician preferences in each institution.
\end{abstract}

Keywords: Neurocritical care, Protocols, Guidelines, Pathophysiology, Shivering, Neurological prognostication, Delayed cerebral ischemia, Nonconvulsive status epilepticus, Psychosis, Seizure

\section{Background}

The art of neurocritical care requires an understanding of the pathophysiology of the highly complex central nervous system. Because of its complexity and the lack of evidence, the approach to neurocritical care is often clinician-dependent, i.e., driven by anecdotal experience and physician preferences, which leads to care variation. Overall, standardization of practice has improved outcomes for many critical conditions in the intensive care unit; thus, greater emphasis should be placed on reducing variation in neurocritical care practice.

Guideline- and pathophysiology-based protocols are concise yet comprehensive and are useful for bedside clinicians who need to provide consistent, standardized

\footnotetext{
* Correspondence: norisue.yasuhiro@gmail.com

'Department of Emergency and Critical Care Medicine, Tokyo Bay Urayasu Ichikawa Medical Center, 3-4-32 Todaijima, Urayasu, Chiba 2790001, Japan ${ }^{2}$ Department of Emergency and Critical Care Medicine, St. Marianna University Hospital, 2-16-1, Sugao, Kawasaki, Kanagawa 2168511, Japan Full list of author information is available at the end of the article
}

practice in a dynamic clinical environment. We introduce five preliminary protocols in this article. Because most of the text of the protocols addresses management in neurocritical care fields that lack firm evidence, and because of the varied availability of medical resources among institutions, we recommend that these protocols be used as drafts to be customized for the systems, environments, and clinical preferences of each institution.

\section{Protocols}

Prompt shivering management (Fig. 1)

Shivering is a physiological homeostatic response to maintain or raise temperature in hypothermia or fever when the set point temperature is elevated. However, shivering counteracts the effort of fever management and targeted temperature management (TTM)/therapeutic hypothermia, which are critical interventions to mitigate secondary brain injury. With inadequate shivering management, target temperature is difficult to achieve in a timely manner and may potentially worsen 
Record Bedside Shivering Assessment Scale (BSAS) every 1 hours and notify house officer if BSAS >0

Go to step 1 if BSAS>0
\begin{tabular}{rl|l|} 
The Bedside Shivering Assessment Scale \\
\hline Score & Description \\
\hline 0 & $\begin{array}{l}\text { No shivering noted on palpation of the masseter, } \\
\text { neck, or chest wall and no electrophysiological } \\
\text { evidence of shivering (using ECG) }\end{array}$ \\
\hline 1 & $\begin{array}{l}\text { Electrophysiological evidence of shivering (using } \\
\text { ECG), without clinical evidence of shivering }\end{array}$ \\
\hline 2 & Shivering localized to the neck and/or thorax only \\
\hline 3 & $\begin{array}{l}\text { Shivering involves gross movement of the upper } \\
\text { extremities (in addition to neck and thorax) }\end{array}$ \\
\hline 4 & $\begin{array}{l}\text { Shivering involves gross movements of the trunk, } \\
\text { upper, and lower extremities }\end{array}$ \\
\hline
\end{tabular}

STEP. 1 (Go to step. 2 if BSAS still > 0 in 20 minutes)

- Acetaminophen $1000 \mathrm{mg}$ IV bolus then $650-1000 \mathrm{mg}$ PO every $6 \mathrm{H}$

AND

- Magnesium 2-4g IV bolus; if necessary, followed by $0.5-2 \mathrm{~g} / \mathrm{H}$ for goal 3-4mg/dL (Check Mg level every $6 \mathrm{H}$ )

- Buspirone $30 \mathrm{mg}$ q8H

- Skin counter-warming (e.g. Bair Hugger set at $43^{\circ} \mathrm{C}$ )

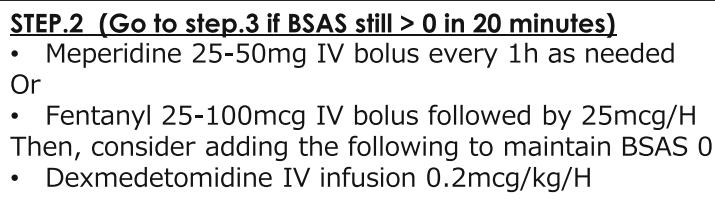

STEP. 3 (Go to step. 4 if BSAS still >0 in 20 minutes) Intubate if not already done

- Propofol 20-40mg bolus IV followed by $30-120 \mathrm{mg} / \mathrm{H}$ if BP tolerates or

- Midazolam bolus 3-5mg IV followed by $2-15 \mathrm{mg} / \mathrm{H}$

STEP.4

- Cisatracurium $0.1-0.2 \mathrm{mg} / \mathrm{kg}$ IV bolus followed by $2-10 \mathrm{mcg} / \mathrm{kg} / \mathrm{min}$

Or

- Rocuronium $0.6-1.2 \mathrm{mg} / \mathrm{kg}$ IV bolus followed by $3-12 \mathrm{mg} / \mathrm{H}$

Wean paralytics to maintain BSAS score 0 and 1-2 twitches on Train of Four (TOF)

Fig. 1 Preliminary protocol for prompt shivering management [1, 2]. Modified from Brophy [2] with permission. Abbreviations: BSAS Bedside Shivering Assessment Scale, ECG electrocardiogram, IV intravenously, PO per oral, H hour, min minute

outcome. Furthermore, shivering increases the cerebral metabolic rate and may result in increased intracranial pressure (ICP) and brain oxygen consumption [1, 2]. Lastly, shivering increases the total body metabolic rate and total $\mathrm{CO}_{2}$ production, which may raise the partial pressure of $\mathrm{CO}_{2}$ and raise ICP. Therefore, shivering should be regarded as a neurological emergency requiring immediate control in patients with acute brain injury, and any protocol for shivering management should encourage clinicians to expedite treatment. The present draft proposal for shivering management refers to the Bedside Shivering Assessment Scale and shivering protocol proposed by Badjatia and Brophy, respectively, $[1,2]$ and was refined, based on our practice, to achieve prompt shivering control (Fig. 1).

\section{Traumatic brain injury and ICP management (Fig. 2)}

Intracranial hypertension, commonly defined as persistent elevation of ICP above $20-22 \mathrm{mmHg}$, is a relatively common neurologic complication seen after traumatic brain injury (TBI). If untreated, it can lead to cerebral ischemia, brain herniation, and possibly brain death. Therefore, care providers must promptly recognize the early clinical and radiographic features of elevated ICP and aggressively treat with a goal of reducing mortality and morbidity. The adult brain is a nearly incompressible substance enclosed in a fixed cranium. Therefore, ICP will inevitably be affected by a volume change in any of the three main intracranial components-cerebrospinal fluid (CSF), brain parenchyma, and blood [3]. In addition, if there is a new space-occupying lesion within the fixed cranium (i.e., hematoma), it will inevitably increase ICP. When assessing a patient with elevated ICP, it is important to determine whether the contributing factor is a focal, global, or mixed process since the treatment strategy may be different for each type of mass effect. If there is a focal, new mass-occupying lesion that is causing a regional mass effect and brain tissue compression, the 
Step 1: Does the patient need surgical intervention?

Indications for surgical intervention

- Epidural hematoma (EDH) larger than $30 \mathrm{~mL}$ in volume using the $A B C / 2$ method regardless of the Glasgow Coma Scale (GCS) score

- EDH (even <30ml) and coma (GCS score $\leq 8$ ) who have pupillary abnormalities (anisocoria)

- Subdural hematomas (SDH) $>10 \mathrm{~mm}$ in thickness or associated with midline shift $>5 \mathrm{~mm}$ on CT regardless of the patient's GCS score

- SDH and coma (GCS score is $\leq 8$ ) or decreased GCS by $\geq 2$ points from the time of injury to hospital admission, and/or the patient presents with asymmetric or fixed and dilated pupils when no other intracranial pathologies such as cerebral edema, diffuse axonal injury or hemorrhagic contusion or intracerebral hemorrhage that could account for the worsening neurological exam.

- Traumatic intracerebral hemorrhage $(\mathrm{ICH})$ in the posterior fossa with evidence of significant mass effect (distortion, dislocation, obliteration of the fourth ventricle, compression of the basal cisterns, or obstructive hydrocephalus)

- Traumatic $\mathrm{ICH}$ with the hemorrhage $>50 \mathrm{~cm}^{3}$ in volume using the $\mathrm{ABC} / 2$ method.

- Traumatic ICH with the GCS score of 6 to 8 in a patient with a frontal or temporal hemorrhage greater than $20 \mathrm{~cm}^{3} \mathrm{using}$ the $\mathrm{ABC} / 2$ method with midline shift of at least $5 \mathrm{~mm}$ and/or cisternal compression on CT scan

- Penetrating injury

- Open skull fractures depressed greater than the thickness of the cranium or with dural penetration, significant intracranial hematoma, frontal sinus involvement, cosmetic deformity, wound infection or contamination, or pneumocephalus

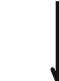

\section{Step 2: Does the patient have coagulopathy?}

Reverse coagulopathy

- Antiplatelet: Platelet transfusion only if undergoing neurosurgery; a single dose of desmopressin (DDAVP) $0.4 \mathrm{mg} / \mathrm{kg}$ ) may be considered

- Unfractionated Heparin: protamine sulfate $1-1.5 \mathrm{mg} / 100$ unit heparin over past 2-3H, up to max $50 \mathrm{mg}$ over $10 \mathrm{~min}$

- Warfarin: PCC or $15 \mathrm{ml} / \mathrm{kg}$ FFP and Vitamin K $10 \mathrm{mg}$ IV if severe; Vitamin K alone in non-life-threatening cases

- Enoxaparin: 1:1 dose protamine sulfate: enoxaparin (if < $8 \mathrm{~h}$ after dose) Max dose: $50 \mathrm{mg}$ over $10 \mathrm{~min}$

- Dabigatran : Idarucizumab $5 \mathrm{~g}$ IV doses over $10 \mathrm{~min}$, HD, activated charcoal (if $<2 \mathrm{H}$ after last dose)

- Rivaroxaban, Apixaban, Edoxaban: No specific antidote; 4PCC (Kcentra) at 25-50U/kg or 3PCC (Bebulin; Profilnine) if 4PCC unavailable

- Alteplase (tPA) :No specific antidote; consider $10 \mathrm{U}$ of cryoprecipitate, antifibrinolytic agent, factor VII, 6-8U platelets

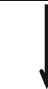

Step 3: Does the patient need ICP monitoring?

Indications

- All salvageable patients with a severe traumatic brain injury (GCS 3-8 after resuscitation)

- Abnormal CT (hematomas, contusion, swelling, herniation, compressed basal cisterns).

- Abnormal CT + if two or more of the following features: age $\geqq 40$, unilateral or bilateral motor posturing, or $S B P<90$

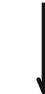

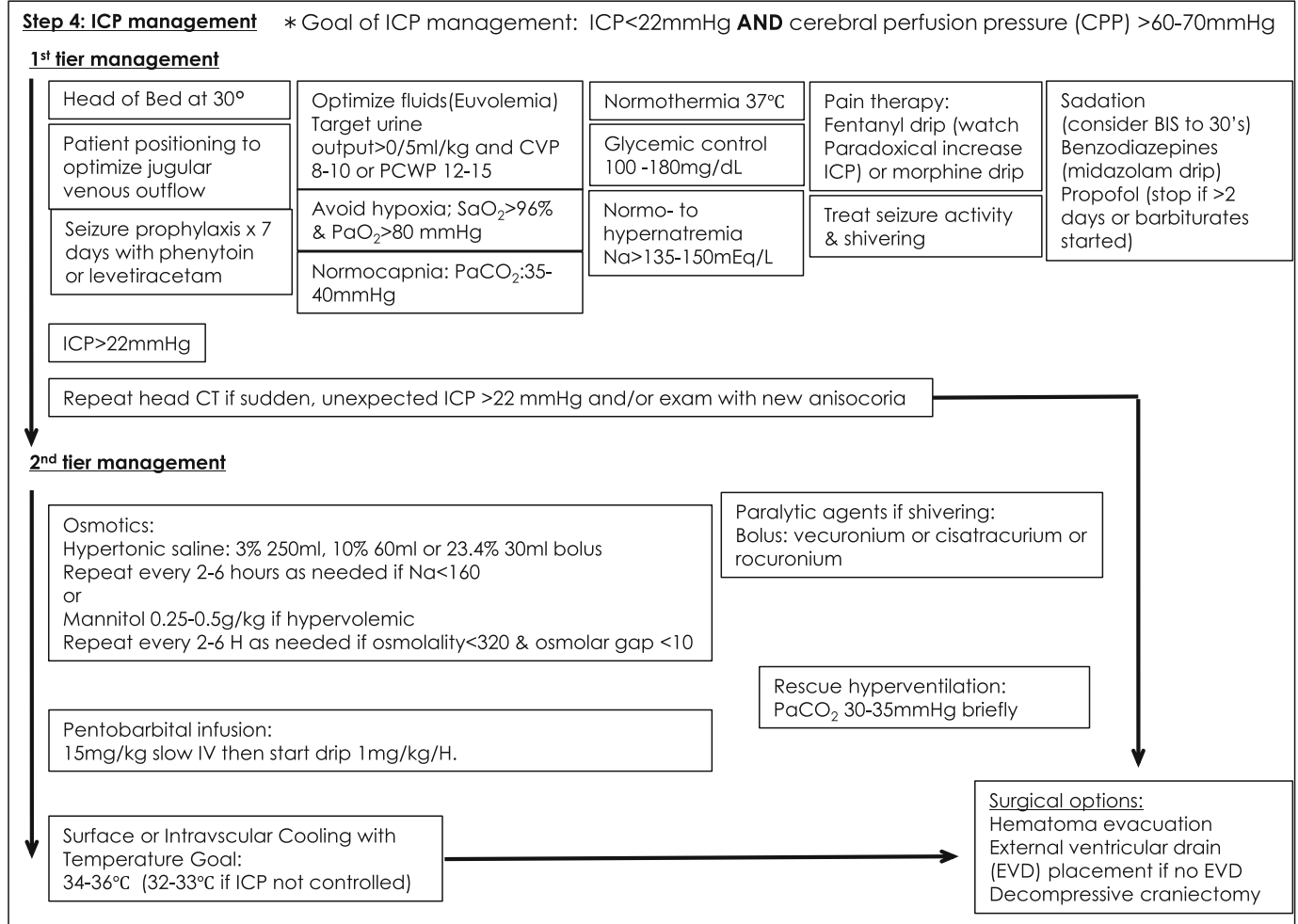

Fig. 2 (See legend on next page.) 
(See figure on previous page.)

Fig. 2 Preliminary protocol for traumatic brain injury and ICP management [4-8]. Abbreviations: CT computed tomography, SBP systolic blood pressure, $\mathrm{U}$ units, 3PCC 3-factor prothrombin complex concentrate, 4PCC 4-factor prothrombin complex concentrate, ICP intracranial pressure, CVP central venous pressure, PCWP pulmonary capillary wedge pressure, $\mathrm{SaO}_{2}$ arterial oxygen saturation, $\mathrm{PaO}_{2}$ arterial pressure of oxygen, $\mathrm{PaCO} 2$ arterial pressure of carbon dioxide

first step is to consider surgical evacuation. Once the focal mass effect is ruled out or treated, global elevation of ICP must be addressed. The overarching strategy to control globally elevated ICP is to (1) optimize cerebral perfusion, oxygenation, and venous drainage; (2) prevent fever, hypercapnia, hyponatremia, hypo/hyperglycemia, and seizure; (3) provide adequate cerebral metabolic suppression with sedation; and (4) reduce cerebral edema with osmotic therapy. For refractory intracranial hypertension, treatments to be considered include pentobarbital-induced coma, therapeutic hypothermia, ventriculostomy placement for CSF diversion, and decompressive craniectomy. Ideally, a protocol for TBI management should include not only ICP control but also indications of initial surgical intervention for intracranial hematoma and basic management to prevent secondary brain injury. Step 1 (indications for surgical intervention) of the preliminary protocol is based on the recommendations by Bullock et al. [4-7], and step 2 (indications for ICP monitoring) and step 3 (basic management of TBI and ICP control) were developed in accordance with the guidelines for management of severe traumatic brain injury of the Brain Trauma Foundation and our practice (Fig. 2) [8].

Neurological prognostication after cardiac arrest (Fig. 3) Cardiac arrest causes complete cessation of cerebral perfusion and rapidly depletes oxygen and glucose delivery to cerebral tissue. Cell death, which includes ion channel dysfunction and cell membrane destabilization, release

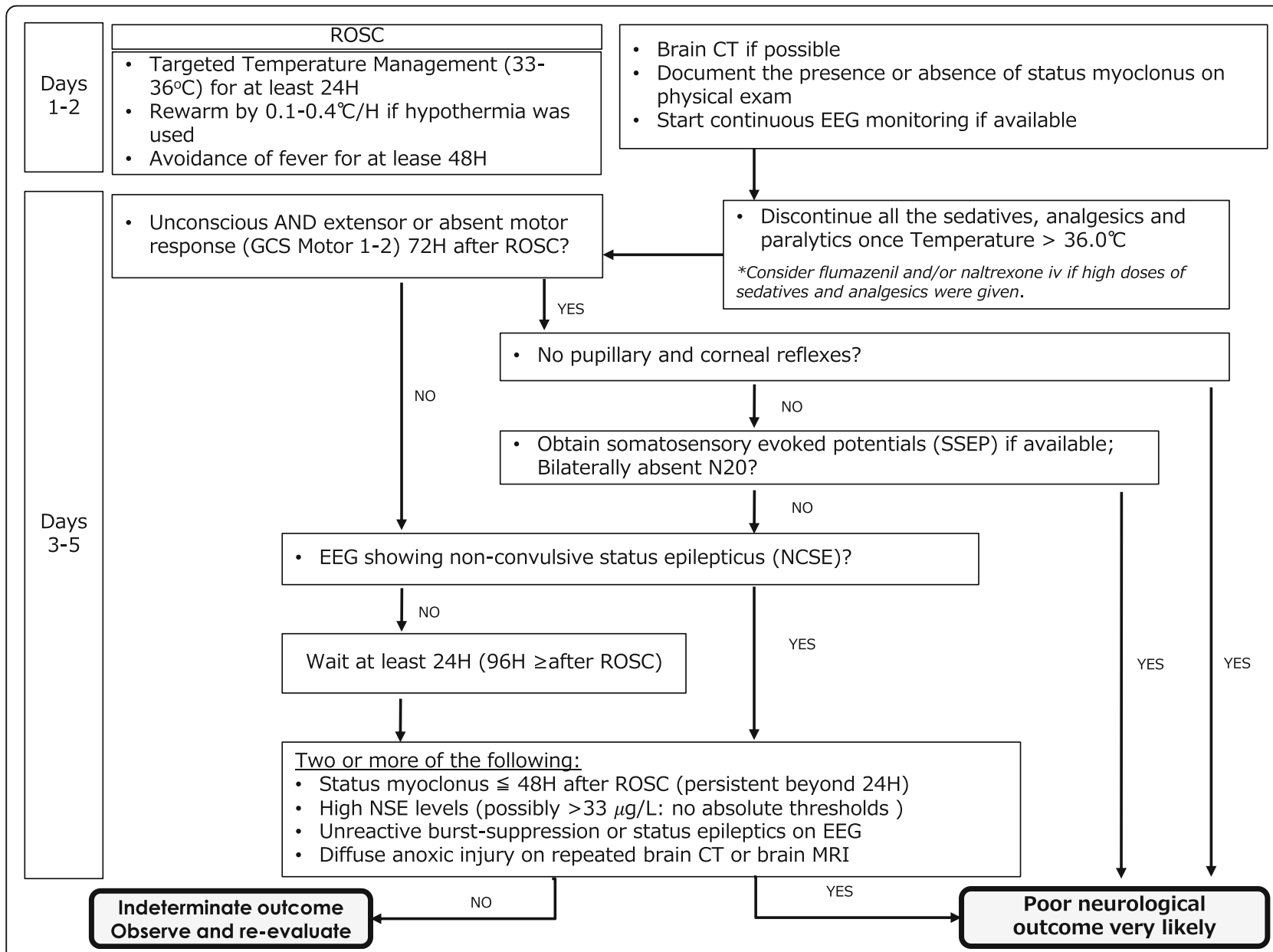

Fig. 3 Preliminary protocol for neurological prognostication after cardiac arrest [13, 16]. Modified from Nolan [13] with permission. Abbreviations: ROSC return of spontaneous circulation, EEG electroencephalography 


\section{Baseline management}

- Maintain head-of-bed at 30 degrees

Hold an

secured

Aneurysm repair within $24 \mathrm{H}$

- Systolic blood pressure $<140 \mathrm{mmHg}$ before aneurysm

repair

- Systolic blood pressure $<180 \mathrm{mmHg}$ (immediately post aneurysmal repair if no vasospasm after aneurysm repair

- Nimodipine $60 \mathrm{mg}$ orally every $4 \mathrm{H}$ for 21 days $(30 \mathrm{mg}$ every $2 \mathrm{H}$ if hypotension side effect is significant)
- Start DVT chemoprophylaxis on day 2-3 if bleeding is controlled.

- Aspirin after coil embolization

- Routine use of seizure prophylaxis is not indicated unless clinical seizure was present.

- Fever and shivering management per protocol

- Insert ventriculostomy for obstructive hydrocephalus

- ICP management for elevated ICP per protocol

- Sodium level 135-145meq/L

- Avoid hypotonic or dextrose containing IV fluids

- Maintain blood glucose 100-180 mg/dl

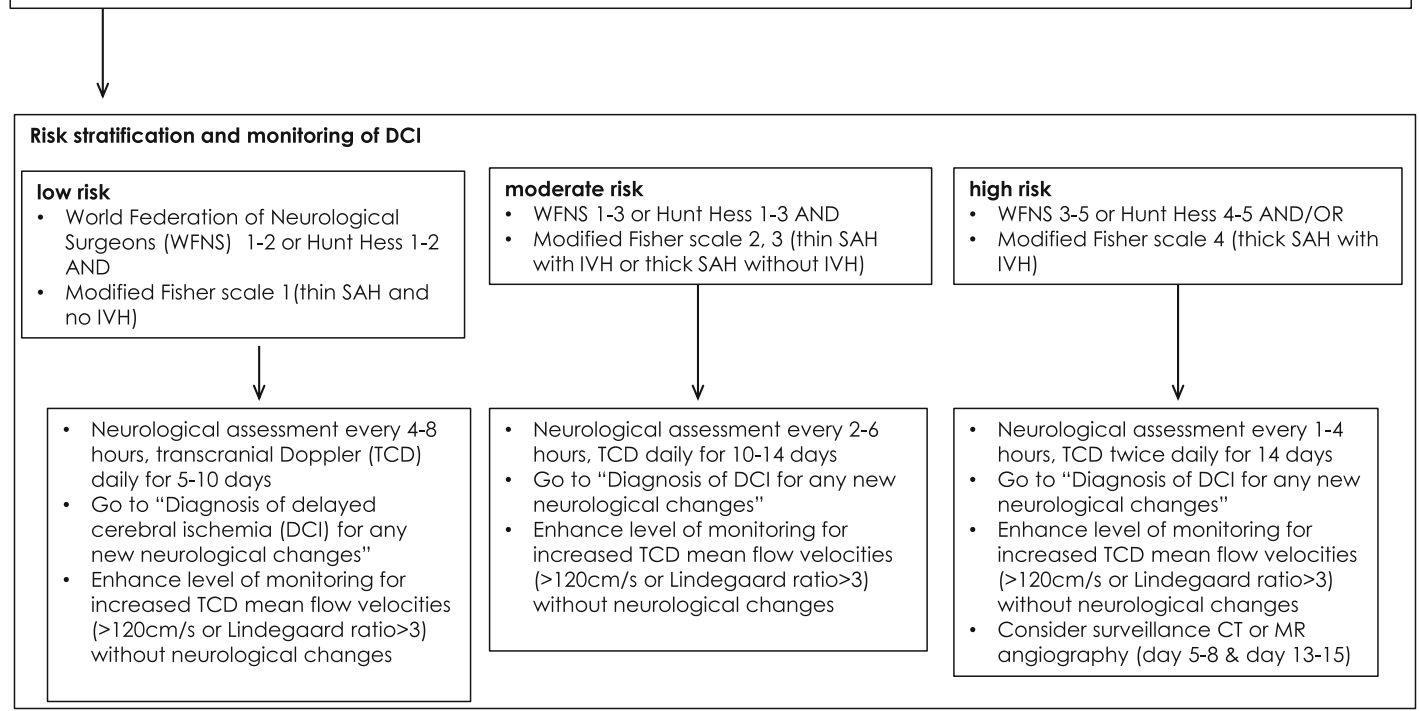

Diagnosis of $\mathrm{DCl}$

Rule out and treat other possible causes for neurological

- Neurological deterioration ( $\downarrow G C S \geqq 2$ points or $\uparrow N I H S S \geqq 2$ points)

changes

- New focal neurologic deficits lasting for at least 1 hour

- Seizures

-

- Increased ICP

Hydrocephalus

- Re-bleeding

- Hyponatremia

- Infection

- Drugs: sedatives, anesthetics, opioids

Findings supporting diagnosis of $\mathrm{DCl}$

- DSA or CTA : severe angiographic vasospasm/defined as a narrowing of at least $70 \%$ from baseline

- TCD:

- Mean flow velocities $>180 \mathrm{~cm} / \mathrm{s}$ or Lindegaard ratio $>6$ (severe)

- Mean flow velocities $140-180 \mathrm{~cm} / \mathrm{s}$ or Lindegaard ratio 4-6 (moderate)

- Mean flow velocities $120-140 \mathrm{~cm} / \mathrm{sec}$ or Linegaard ratio 3-4 (mild)

- CT perfusion parameters: $\mathrm{CBF}>25 \mathrm{ml} / 100 \mathrm{~g} /$ minute, $\mathrm{MTT}$ (mean transit times) $>6.5$ seconds

- EEG : reduced alpha variability

- PbtO2 : <20mmHg

- Cerebral microdialysis (CMD) : LPR $>40$, glucose $<0.5 \mathrm{mM}$, glutamate $>40 \mathrm{mM}$

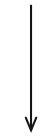

\section{Treatment of $\mathrm{DCl}$}

(1) $500-1000 \mathrm{ml}$ crystalloid bolus

Target euvolemia (hypervolemia is not superior than euvolemia) and evaluate neurological fluid responsiveness

(2) Induced hypertension

Start phenylephrine or noradrenaline after excluding intracranial hemorrhage on CT

Increase vasopressor to titrate up SBP by $10 \mathrm{mmHg}$ to SBP $160-220 \mathrm{mmHg}$ until neurological improvements

(3) inotropic agents

Start dobutamine or milrinone if cardiac function is low (i.e. Takotsubo or baseline cardiomyopathy)

(4) intra-arterial therapy

Percutaneous balloon angioplasty / intra-arterial vasodilators (i.e., Calcium-channel blocker)

Fig. 4 Preliminary protocol for monitoring and diagnosis of delayed cerebral ischemia after subarachnoid hemorrhage [23, 24]. Abbreviations: SAH subarachnoid hemorrhage, DVT deep vein thrombosis, IVH intraventricular hemorrhage 
of destructive enzymes, cell swelling, and, eventually, apoptosis, can begin within $5 \mathrm{~min}$ after complete cessation of cerebral perfusion [9-11]. After return of spontaneous circulation, neurological prognostication is essential because it enables clinicians to provide information to family members or surrogates who must consider decisions to limit care for patients with little hope of meaningful neurological recovery [11]. To date, there is no definitive diagnostic test to accurately predict functional outcome after cardiac arrest. Moreover, clinical findings shortly after cardiac arrest have little relationship to patient outcomes [12]. However, the use of a systematic approach allows for reliable prediction of a very poor neurological outcome (persistent vegetative state) and provides family members and surrogates with the information necessary to make decisions [13-16]. A protocol that clearly addresses "what to do next" would be helpful for clinicians. The present preliminary protocol is based on the 2015 European Society of Intensive Care Medicine Guidelines for Post-resuscitation Care [13], but includes additional detailed stepwise instructions (Fig. 3).

\section{Delayed cerebral ischemia after subarachnoid hemorrhage (Fig. 4)}

After subarachnoid hemorrhage, notably from a ruptured cerebral aneurysm, cerebral vasospasm can develop, thus leading to delayed cerebral ischemia (DCI) and possibly infarction. The mechanism of DCI is complex and is not solely attributed to large-vessel narrowing and associated low blood flow distally $[17,18]$. Other postulated mechanisms are early brain injury, microcirculatory dysfunction with loss of cerebral autoregulation, cortical spreading depolarization, and microthrombosis [19, 20]. A DCI diagnosis is made clinically on the basis of symptoms such as new changes in mental status and neurologic deficits. Additional relevant information includes findings of CT or MRI angiography, digital subtraction angiography, and transcranial Doppler (TCD) ultrasound. In addition, other reversible causes of neurological changes must be ruled out, such as delayed hydrocephalus, nonconvulsive seizure, rebleeding, toxic-metabolic encephalopathy from infection, and medication side effects. To date, nimodipine, a calcium-channel blocker with cerebral vasodilatory

\section{NCSE protocol for patients without known epileptic encephalopathy}

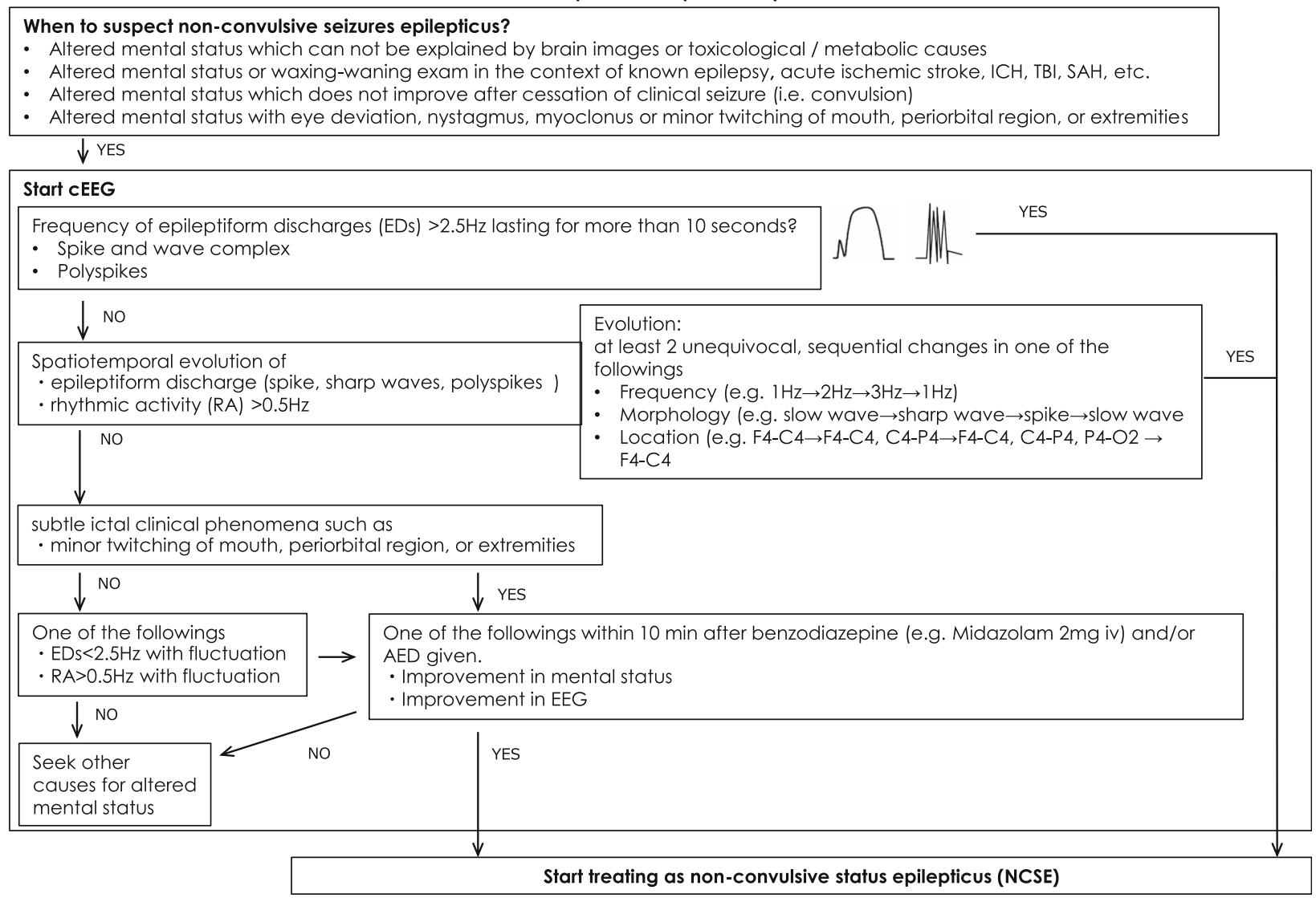

Fig. 5 Preliminary protocol for diagnosis of nonconvulsive status epilepticus [32]. Abbreviations: AED anti-epileptic drug 


\begin{tabular}{|c|c|c|c|}
\hline \multicolumn{4}{|c|}{$\begin{array}{l}\text { Step 1: Differential diagnoses and evaluations } \\
\text { - Drug: Urine toxicology screening } \\
\text { - Bacterial or fungal meningitis/encephalitis: Cerebrospinal fluid (CSF) glucose, protein, cell count with differential, VDRL, bacterial } \\
\text { culture, acid-fast bacilli (AFB) culture, Cryptococcus culture, serum Lyme antibody } \\
\text { - Viral encephalitis: Brain MRI with contrast, CSF glucose, protein, cell count with differential, CSF HSVI/2 CPR and VZV PCR (EPstein-Barr } \\
\text { virus PCR, CMV PCR and HIV RNA if serum HIV positive) } \\
\text { - Hashimoto encephalopathy: anti-TPO antibody, anti-Thyroglobulin antibody } \\
\text { - Acute disseminated encephalomyelitis (ADEM): Check for preceding infection or vaccination, brain MRI with contrast } \\
\text { - Reversible posterior leukoencephalopathy syndrome: Brain MRI, check for history of preceding visual disturbance, episode of acute } \\
\text { severe hypertension and causative agent such as cyclosporine, tacrolimus and cisplatin. } \\
\text { - Leptomeningeal metastasis: CSF cytology, Brain MRI with contrast } \\
\text { - CNS Vasculitis: serum ANA, ANCA, CT/MR angiography or conventional angiography }\end{array}$} \\
\hline$\downarrow \quad$ No clear diagnosis & & & \\
\hline \multicolumn{4}{|c|}{ Step 2: Evaluate the possibility of autoimmune encephalitis with Antibody Prevalence in Epilepsy (APE) score } \\
\hline Clinical Feature & Value & & \multirow{11}{*}{$\begin{array}{l}\text { Seek other } \\
\text { causes }\end{array}$} \\
\hline $\begin{array}{l}\text { New-onset, rapidly progressive mental status changes of } 1-6 \text { weeks, or new-onset seizure } \\
\text { activity }\end{array}$ & 1 & & \\
\hline Neuropsychiatric changes; agitation, aggressiveness, emotional lability & 1 & & \\
\hline $\begin{array}{l}\text { Autonomic dysfunction (presenting as labile blood pressure, labile heart rate, persistent } \\
\text { tachycardia, postural hypotension) }\end{array}$ & 1 & & \\
\hline $\begin{array}{l}\text { Viral prodrome (runny nose, sore throat, low-grade fever), only to be scored in the absence } \\
\text { of underlying malignancy }\end{array}$ & 2 & & \\
\hline Facial dyskinesias or faciobrachial dystonic movements & 2 & & \\
\hline Seizure refractory to at least 2 anti seizure medications & 2 & & \\
\hline $\begin{array}{l}\text { CSF findings consistent with inflammation (elevated CSF protein level }>50 \mathrm{mg} / \mathrm{dll} \text { and/or } \\
\text { lymphocytic pleocytosis }>5 \mathrm{cells} / \mathrm{dll} \text {, if the total number of CSF RBCs is }<1000 \mathrm{cells} / \mathrm{dll} \text { ) }\end{array}$ & 2 & & \\
\hline $\begin{array}{l}\text { Brain MRI showing signal changes consistent with limbic encephalitis (medial temporal } \\
\text { T2/FLAIR signal changes) }\end{array}$ & 2 & & \\
\hline $\begin{array}{l}\text { Presence of underlying malignancy (excluding cutaneous squamous cell or basal cell } \\
\text { carcinomas) }\end{array}$ & 2 & & \\
\hline Total & 15 & & \\
\hline
\end{tabular}

Step 3: Send autoimmune encephalitis panel for serum and CSF
-antibodies against intracellular antigens
\begin{tabular}{|l|l|l|}
\hline Antibody & Tumor association & $\begin{array}{l}\text { Characteristic clinical features } \\
\text { besides to acute psychosis and } \\
\text { seizure }\end{array}$ \\
\hline Hu(ANNA-1) & $\begin{array}{l}\text { Small cell lung cancer } \\
\text { (SCLC) }\end{array}$ & $\begin{array}{l}\text { Encephalomyelitis, cerebellar } \\
\text { ataxia, Sensory neuropathy (not } \\
\text { peripheral neuropathy) }\end{array}$ \\
\hline CV2(CRMP5) & SCLC, thymoma & $\begin{array}{l}\text { Cerebellar ataxia, sensory } \\
\text { neuropathy, uveititis, optic neuritis }\end{array}$ \\
\hline Ri(ANNA2) & Breast cancer & Opsoclonus-myoclonus ataxia \\
\hline Yo(PCA1) & ovarian tumor & Cerebellar ataxia \\
\hline Tr & Hodgkin & Cerebellar ataxia \\
\hline Ma2 & Testicular, Lung cancer & $\begin{array}{l}\text { Hypersomnolence, vertical gaze } \\
\text { paresis, cerebellar ataxia, }\end{array}$ \\
\hline recoverin & SCLC & Retinopathy \\
\hline zic4 & SCLC & Cerebellar ataxia \\
\hline GAD & Thymoma, SCLC & Cerebellar ataxia \\
\hline
\end{tabular}

- antibodies against cell surface or synaptic proteins

\begin{tabular}{|c|c|c|}
\hline Antibody & Tumor association & $\begin{array}{l}\text { Characteristic clinical features } \\
\text { besides acute psychosis and } \\
\text { seizure }\end{array}$ \\
\hline NMDAr & Ovarian teratomas & $\begin{array}{l}\text { Preceding Insomnia, memory and } \\
\text { behavioral disturbance }\end{array}$ \\
\hline VGKC & Thymoma & \\
\hline AMPAr & $\begin{array}{l}\text { SCLC, Breast, Thymoma, } \\
\text { Ovarian teratomas }\end{array}$ & \\
\hline LGI1 & Lung cancer, Thymoma & Facio-brachial dystonic seizures \\
\hline CASPR2 & Thymoma & $\begin{array}{l}\text { Neuropathic pain, peripheral } \\
\text { neuropathy, cerebellar atacxia }\end{array}$ \\
\hline GABA $A_{8} r$ & $\begin{array}{l}\text { Thymoma, SCLC } \\
\text { paraneoplastic: } 50 \%\end{array}$ & \\
\hline$G_{A B A_{A} r}$ & Thymoma & Refractory seizures \\
\hline GlycineR & Lung cancer, Hodgkin & $\begin{array}{l}\text { Encephalomyelitis with muscle } \\
\text { spasm, rigidity, myoclonus }\end{array}$ \\
\hline mGluR5 & Hodgkin & \\
\hline DPPX & Lymphoma & Preceding weight loss, diarrhea. \\
\hline Dopamine & Non-paraneoplastic & \\
\hline MOG & & \\
\hline Aquaporin4 & & \\
\hline GQ1b & & \\
\hline
\end{tabular}

CT scan of the chest, abdomen, pelvis with contrast for tumor screening prior to return of the results.

\section{Step 4: Modify treatments once the antibody results are back}

\begin{tabular}{|l|l|}
\hline $\begin{array}{l}\text { contibodies against intracellular antigens } \\
\text { as rituximab or cyclophosphamide }\end{array}$ & $\begin{array}{l}\text { - antibodies against cell surface or synaptic proteins } \\
\text { continue first-line treatment(steroids, IVIG, or plasma } \\
\text { exchange) } \\
\text { consider adding second-line treatment if no clinical } \\
\text { improvement }\end{array}$ \\
\hline
\end{tabular}

- antibodies negative
consider adding second-line
treatment if no clinical improvement
Re-evaluate for other causes
especially infectious causes

Fig. 6 Preliminary protocol for acute or subacute psychosis and newly onset seizure [33, 35]. Modified from Dubey [33] with permission. Abbreviations: VDRL venereal disease research laboratory, HSV herpes simplex virus, VZV varicella zoster virus, HIV human immunodeficiency virus, CMV cytomegalovirus, Anti-TPO anti-thyroid peroxidase, ANA anti-nuclear antibody, ANCA antineutrophil cytoplasmic antibody 
effect, is the only drug that has been shown to improve neurological outcomes in patients with subarachnoid hemorrhage [21]. Other calcium-channel blockers, such as nicardipine, have been used in countries where nimodipine is unavailable [22] but have not been shown to improve outcomes. Hemodynamic augmentation to increase oxygen delivery to the brain, including volume optimization and induced hypertension, is the mainstay for management of new-onset DCI. For refractory cases where medical management is ineffective, intra-arterial interventions such as balloon angioplasty and intra-arterial administration of calcium-channel blockers are a second-line treatment [23]. A protocol should include risk stratification and stepwise treatment for DCI in individual patients. The present preliminary protocol describes basic management of subarachnoid hemorrhage and risk stratification and monitoring, based on our practice and the existing literature [24-26]. Diagnosis and management of DCI are based on recommendations from the neurocritical care society and our practice [23] (Fig. 4).

\section{Diagnosis of nonconvulsive status epilepticus (Fig. 5)}

Nonconvulsive status epilepticus (NCSE) is characterized by electrographic seizure activity without clinical convulsions in patients who do not fully recover consciousness between attacks [27]. Although the impact of treating NCSE on clinical outcomes has not been investigated in a randomized controlled trial, the prognosis of NCSE is believed to be poor if not treated since untreated seizure is associated with secondary brain injury [28-30]. A diagnosis of NCSE should be considered in any patient with discrepancies between his/her neurological findings and clinical history or imaging findings such as CT or MRI. The typical example is a patient who develops sudden unexpected neurological deterioration after successful management of a structural brain injury without new findings on CT or MRI. Although the condition is referred to as nonconvulsive, patients with NCSE may have subtle motor symptoms such as sustained eye deviation, nystagmus, lip smacking, and twitching in the face or extremities [31]. Definitive diagnosis requires electroencephalography (EEG), and continuous EEG monitoring increases the sensitivity and specificity of NCSE diagnosis. We attempted to develop an algorithmic protocol to interpret EEG and diagnose NCSE for bedside clinical use. Based on the current guidelines [27, 32], this draft protocol for diagnosis of NCSE is designed to simplify NCSE diagnosis and management (Fig. 5).

\section{Acute or subacute psychosis and seizure (Fig. 6)}

Many medical conditions and pharmacologic side effects can cause unexpected psychosis or seizure. However, some treatable and reversible conditions, such as viral encephalitis and autoimmune encephalitis, are frequently missed.
Delays in diagnosis and treatment of encephalitis may result in poor neurological outcomes. It is essential to review all possible causes of unexpected psychosis and seizure and to start empirical treatment for a potentially treatable condition before obtaining all examination results. The present draft protocol for diagnosis and management of autoimmune encephalitis includes comprehensive differential diagnoses and algorithms for diagnostic evaluation and was developed on the basis of a comprehensive literature review by Francesc et al., antibody prevalence in epilepsy (APE) score [33], and empirical treatment for autoimmune encephalitis in cases of unexpected psychosis or seizure, as reflected by the expert opinions of the European Federation of the Neurological Societies (EFNS) task force [34] and our practice (Fig. 6).

\section{Conclusion}

The present guideline- and pathophysiology-based protocols that can be customized for particular clinical environments may help providing consistent, standardized care in neurocritical care. Because most of the contents of presented protocol are not supported by evidence, they should be validated in a prospective controlled study in future.

\section{Abbreviations \\ CSF: Cerebrospinal fluid; DCl: Delayed cerebral ischemia; EEG: Electroencephalography; ICP: Intracranial pressure; NCSE: Nonconvulsive status epilepticus; TBI: Traumatic brain injury; TCD: Transcranial Doppler; TTM: Targeted temperature management}

\section{Author contributions}

YN is the guarantor of the manuscript content and protocols. YF and KN substantially contributed to the manuscript and protocols. All authors read and approved the final manuscript.

Ethics approval and consent to participate Not applicable

Consent for publication Not required

Competing interests

The authors declare that they have no competing interests.

\section{Publisher's Note}

Springer Nature remains neutral with regard to jurisdictional claims in published maps and institutional affiliations.

\section{Author details}

${ }^{1}$ Department of Emergency and Critical Care Medicine, Tokyo Bay Urayasu Ichikawa Medical Center, 3-4-32 Todaijima, Urayasu, Chiba 2790001, Japan. ${ }^{2}$ Department of Emergency and Critical Care Medicine, St. Marianna University Hospital, 2-16-1, Sugao, Kawasaki, Kanagawa 2168511, Japan. ${ }^{3}$ Department of Medicine, Division of Neurology, John A. Burns School of Medicine University of Hawai`i, 1301 Punchbowl Street, Honolulu, HI 96813 USA. 
Received: 12 April 2018 Accepted: 27 July 2018

Published online: 07 August 2018

\section{References}

1. Badjatia N, Strongilis E, Gordon E, Prescutti M, Fernandez L, Fernandez A, Buitrago M, Schmidt JM, Ostapkovich ND, Mayer SA. Metabolic impact of shivering during therapeutic temperature modulation: the Bedside Shivering Assessment Scale. Stroke. 2008;39(12):3242-7.

2. Brophy GM, Human T. Pharmacotherapy pearls for emergency neurological life support. Neurocrit Care. 2017;27(Suppl 1):51-73.

3. Fishman RA. Cerebrospinal fluid in diseases of the nervous system. Philadelphia: London: Saunders; 1980.

4. Bullock MR, Chesnut R, Ghajar J, Gordon D, Hartl R, Newell DW, Servadei F, Walters BC, Wilberger J, Surgical Management of Traumatic Brain Injury Author G. Surgical management of posterior fossa mass lesions. Neurosurgery. 2006;58(3 Suppl):S47-55. discussion Si-iv

5. Bullock MR, Chesnut R, Ghajar J, Gordon D, Hartl R, Newell DW, Servadei F, Walters BC, Wilberger J, Surgical Management of Traumatic Brain Injury Author G. Surgical management of depressed cranial fractures. Neurosurgery. 2006;58(3 Suppl):S56-60. discussion Si-iv

6. Bullock MR, Chesnut R, Ghajar J, Gordon D, Hartl R, Newell DW, Servadei F, Walters BC, Wilberger JE, Surgical Management of Traumatic Brain Injury Author G. Surgical management of acute epidural hematomas. Neurosurgery. 2006;58(3 Suppl):S7-15. discussion Si-iv

7. Bullock MR, Chesnut R, Ghajar J, Gordon D, Hartl R, Newell DW, Servadei F, Walters BC, Wilberger JE, Surgical Management of Traumatic Brain Injury Author G. Surgical management of acute subdural hematomas. Neurosurgery. 2006:58(3 Suppl):S16-24. discussion Si-iv

8. Carney N, Totten AM, O'Reilly C, Ullman JS, Hawryluk GW, Bell MJ, Bratton SL, Chesnut R, Harris OA, Kissoon N, et al. Guidelines for the management of severe traumatic brain injury, fourth edition. Neurosurgery. 2017;80(1):6-15.

9. Neumar RW. Molecular mechanisms of ischemic neuronal injury. Ann Emerg Med. 2000;36(5):483-506.

10. Pulsinelli WA, Brierley JB, Plum F. Temporal profile of neuronal damage in a model of transient forebrain ischemia. Ann Neurol. 1982:11(5):491-8.

11. Lee K. The neurolCU book. 2nd ed. New York: McGraw-Hill Medical; 2017.

12. Rittenberger JC, Sangl J, Wheeler M, Guyette FX, Callaway CW. Association between clinical examination and outcome after cardiac arrest. Resuscitation. 2010:81(9):1128-32.

13. Nolan JP, Soar J, Cariou A, Cronberg T, Moulaert VR, Deakin CD, Bottiger BW, Friberg $\mathrm{H}$, Sunde K, Sandroni C. European Resuscitation Council and European Society of Intensive Care Medicine guidelines for postresuscitation care 2015: section 5 of the European Resuscitation Council guidelines for resuscitation 2015. Resuscitation. 2015:95:202-22.

14. Wijdicks EF, Hijdra A, Young GB, Bassetti CL, Wiebe S, Quality Standards Subcommittee of the American Academy of N. Practice parameter: prediction of outcome in comatose survivors after cardiopulmonary resuscitation (an evidence-based review): report of the Quality Standards Subcommittee of the American Academy of Neurology. Neurology 2006; 67(2):203-210.

15. Zandbergen EG, de Haan RJ, Stoutenbeek CP, Koelman JH, Hijdra A. Systematic review of early prediction of poor outcome in anoxic-ischaemic coma. Lancet. 1998;352(9143):1808-12.

16. Rossetti AO, Rabinstein AA, Oddo M. Neurological prognostication of outcome in patients in coma after cardiac arrest. Lancet Neurol. 2016;15(6): 597-609.

17. Millikan $\mathrm{CH}$. Cerebral vasospasm and ruptured intracranial aneurysm. Arch Neurol. 1975;32(7):433-49.

18. Etminan N, Vergouwen MD, Ilodigwe D, Macdonald RL. Effect of pharmaceutical treatment on vasospasm, delayed cerebral ischemia, and clinical outcome in patients with aneurysmal subarachnoid hemorrhage: a systematic review and meta-analysis. J Cereb Blood Flow Metab. 2011;31(6): $1443-51$.

19. Budohoski KP, Guilfoyle M, Helmy A, Huuskonen T, Czosnyka M, Kirollos R, Menon DK, Pickard JD, Kirkpatrick PJ. The pathophysiology and treatment of delayed cerebral ischaemia following subarachnoid haemorrhage. J Neurol Neurosurg Psychiatry. 2014;85(12):1343-53.

20. Francoeur $\mathrm{CL}$, Mayer SA. Management of delayed cerebral ischemia after subarachnoid hemorrhage. Crit Care. 2016;20(1):277.

21. Petruk KC, West M, Mohr G, Weir BK, Benoit BG, Gentili F, Disney LB, Khan $\mathrm{MI}$, Grace M, Holness RO, et al. Nimodipine treatment in poor-grade aneurysm patients. Results of a multicenter double-blind placebo-controlled trial. J Neurosurg. 1988:68(4):505-17.

22. Tejada JG, Taylor RA, Ugurel MS, Hayakawa M, Lee SK, Chaloupka JC. Safety and feasibility of intra-arterial nicardipine for the treatment of subarachnoid hemorrhage-associated vasospasm: initial clinical experience with high-dose infusions. AJNR Am J Neuroradiol. 2007;28(5):844-8.

23. Diringer MN, Bleck TP, Claude Hemphill J 3rd, Menon D, Shutter L, Vespa P, Bruder N, Connolly ES Jr, Citerio G, Gress D, et al. Critical care management of patients following aneurysmal subarachnoid hemorrhage: recommendations from the Neurocritical Care Society's Multidisciplinary Consensus Conference. Neurocrit Care. 2011;15(2):211-40.

24. Macdonald RL. Delayed neurological deterioration after subarachnoid haemorrhage. Nat Rev Neurol. 2014;10(1):44-58.

25. Frontera JA, Claassen J, Schmidt JM, Wartenberg KE, Temes R, Connolly ES Jr, MacDonald RL, Mayer SA. Prediction of symptomatic vasospasm after subarachnoid hemorrhage: the modified fisher scale. Neurosurgery. 2006; 59(1):21-7. discussion 21-27

26. de Rooij NK, Greving JP, Rinkel GJ, Frijns CJ. Early prediction of delayed cerebral ischemia after subarachnoid hemorrhage: development and validation of a practical risk chart. Stroke. 2013;44(5):1288-94.

27. Brophy GM, Bell R, Claassen J, Alldredge B, Bleck TP, Glauser T, Laroche SM, Riviello JJ Jr, Shutter L, Sperling MR, et al. Guidelines for the evaluation and management of status epilepticus. Neurocrit Care. 2012;17(1):3-23.

28. Towne AR, Pellock JM, Ko D, DeLorenzo RJ. Determinants of mortality in status epilepticus. Epilepsia. 1994;35(1):27-34.

29. DeLorenzo RJ, Garnett LK, Towne AR, Waterhouse EJ, Boggs JG, Morton L, Choudhry MA, Barnes T, Ko D. Comparison of status epilepticus with prolonged seizure episodes lasting from 10 to 29 minutes. Epilepsia. 1999; 40(2):164-9.

30. Waterhouse EJ, Garnett LK, Towne AR, Morton LD, Barnes T, Ko D, DeLorenzo RJ. Prospective population-based study of intermittent and continuous convulsive status epilepticus in Richmond, Virginia. Epilepsia. 1999:40(6):752-8.

31. Husain AM, Horn GJ, Jacobson MP. Non-convulsive status epilepticus: usefulness of clinical features in selecting patients for urgent EEG. J Neurol Neurosurg Psychiatry. 2003;74(2):189-91.

32. Leitinger M, Beniczky S, Rohracher A, Gardella E, Kalss G, Qerama E, Hofler J, Hess Lindberg-Larsen A, Kuchukhidze G, Dobesberger J, et al. Salzburg consensus criteria for non-convulsive status Epilepticus--approach to clinical application. Epilepsy Behav. 2015;49:158-63.

33. Dubey D, Alqallaf A, Hays R, Freeman M, Chen K, Ding K, Agostini M, Vernino S. Neurological autoantibody prevalence in epilepsy of unknown etiology. JAMA Neurol. 2017;74(4):397-402.

34. Vedeler CA, Antoine JC, Giometto B, Graus F, Grisold W, Hart IK, Honnorat J, Sillevis Smitt PA, Verschuuren JJ, Voltz R, et al. Management of paraneoplastic neurological syndromes: report of an EFNS Task Force. Eur J Neurol. 2006;13(7):682-90.

35. Graus F, Delattre JY, Antoine JC, Dalmau J, Giometto B, Grisold W, Honnorat J, Smitt PS, Vedeler C, Verschuuren JJ, et al. Recommended diagnostic criteria for paraneoplastic neurological syndromes. J Neurol Neurosurg Psychiatry. 2004;75(8):1135-40.
Ready to submit your research? Choose BMC and benefit from:
- fast, convenient online submission
- thorough peer review by experienced researchers in your field
- rapid publication on acceptance
- support for research data, including large and complex data types
- gold Open Access which fosters wider collaboration and increased citations
- maximum visibility for your research: over $100 \mathrm{M}$ website views per year
At BMC, research is always in progress.
Learn more biomedcentral.com/submissions 